\title{
Managing Strategic Planning to Better Practice
}

\author{
Thomas Bernard Rowan III \\ Chicago State University, Chicago, USA
}

\begin{abstract}
Strategic planning (SP) is a mainstream practice in higher education today. By virtue of competition, the demand for transparency, and the need to optimize available resources, SP also has become an important part of higher education management. However, SP in practice is no easy thing to manage effectively. Implementing SP meets barriers arising from various factors: faculty motivation, exogenous limits on institutions, and inflexible and formulaic repetition top the list. This paper defines and describes the basic elements of SP. It then discusses sources of negative feedback for SP management before considering how to minimize their side effects. The paper concludes by advancing several candidate conditions for managing SP to best practice. First, SP should incorporate flexibility and autonomy at the unit level (department or office), together with proactive reception and the absence of scapegoating by higher administration. This aspect of aligned planning includes the need to provide some timeline of anticipated gains for units that invest in the process, and a mechanism for identifying and addressing units that underperform. Second, SP should focus not only on issues of new funding requests, but also tie annual reallocations to assessment and make reallocation of existing funding a real possibility. Third, SP should develop institutional networks that cut across offices, departments, colleges, and divisions. Workforce planning should link academic administration across the institution's divisions. Finally, SP requires the integration of cost accounting and estimates for the value of non-instructional, non-revenue generating units. Models of responsibility-based budgeting, load-balancing, and returns on investment are relevant in this regard. Based upon these elements, an institution using aligned SP may be more effectively managed to become a continuous quality improvement organization. Without them, SP can become a rote practice that fulfills mandates or requirements but does not sustain the educational organization.
\end{abstract}

Keywords: strategic planning (SP), higher education, budgeting, assessment, public management

\section{Introduction}

Strategic planning (SP) is not a new process in the realm of higher education. What Rosa, Pedro, and Henrique (2005) discussed as the influence of managerialism in the context of Portuguese higher education would apply in many countries, including the United States. One author described its use as akin to a "war canoe" for difficult fiscal times and the era of public skepticism (Seymour, 2011). Higher education management coins on the use of planning to achieve desired outcomes and to drive initiatives in response to internal and external variables, be they threats or opportunities. In fact, it is empirically likely that the vast majority of institutions already engage in it in some shape, form, or fashion. Annual planning, long-range planning, and mission planning are some of the synonymous terms and forms of SP.

Nonetheless, clarion calls continue about the need for greater "value for money". In an era of widening

Thomas Bernard Rowan III, Ph.D., professor (political science), associate provost, Chicago State University. 
inequality, global publics clamor for greater accountability and transparency in the use of scarce resources. Higher education institutions, in particular public colleges and universities, face skepticism from many citizens about whether academic degrees matter today. Massive online open courses and other forms of education provision, including proprietary and online universities, push the envelope of education reform. Unfortunately, they also twin with cynicism about the importance of higher education. Meanwhile, corporations, governments, and other entities want better educated, highly reflective graduates who exhibit the abilities of critical thinking, skill with metrics, and quantitative information, and who can create advanced processes, designs, and constructions of knowledge in this ever-dynamic world civilization.

This maelstrom of anxiety about and need for quality higher education accents management's role in guiding SP to best practice. Many public institutions face declining public revenues, declining or static enrollment, and rising costs to provide quality education. As such, the inherent value and salience of SP should be further communicated. SP needs wider and better practice in higher education management. It likely is not an exaggeration to assert that without good planning at the institutional level, many colleges and universities may have to close their doors this century.

\section{What Is SP?}

SP incorporates the following six stages or process elements: (a) institutional mission and vision; (b) goals and objectives; (c) desired outcomes; (d) assessments of outcomes; (e) budget priorities tied to the foregoing elements; and (f) use of assessment findings to affirm or revise goals and objectives. SP is a complete system for driving an institution's living mission, and for allocating resources toward improved fulfillment of that mission based upon assessment linked with budgeting. The paper now provides a brief discussion of the six SP elements.

\section{Mission and Vision}

Much of the literature (Aloi, 2005; Kaufman, 2008; Leimer, 2012) stressed the criticality of driving planning with an institution's mission. That certainly is common sense. For a higher education institution, be it a teaching, research, or some other centered organization, it is critical that the mission be defined and couched in such a way to vector its critical operations and provide a framework for collective effort.

It should not go without saying that leadership and vision are vital leavening agents for a mission. Missions can be dead paragraphs of letters without leadership that enlivens and periodically calls for re-evaluation and updating of the institution's mission. In related fashion, institutional strategic plans incorporate vision statements that extend to the future, that actuate mission statements. If a mission says what an institution "is", a vision states what it "will be" consonant with that mission. Leadership drives SP management administration and exhorts faculty, staff, students, and community partners to the mission (Taylor, De Lourdes Machado, \& Peterson, 2008). A condition for effective SP is management by leadership that believes in, speaks to, and inculcates the institution's mission (Deming, 1982). This is best demonstrated by senior leadership units themselves preparing unit plans to align with the institutional strategic plan.

Finally, a critical flashpoint for better-to-best practice in SP is the extent to which the organization's stakeholders empirically accept and want to fulfill the institution's mission. That is to say, one test condition for effective SP is whether there is a working degree of consensus on the mission and its elaboration in a given strategic plan. Kezar (2005) accented the role of SP as a vehicle for organizational learning. M. C. Choban, G. 
M. Choban, and D. Choban (2008), Welsh, Nunez, and Petrosko (2006), and Welsh and Nunez (2005) noted the necessary condition of motivation on the part of stakeholders for effective SP. Unless the mission, as elaborated by the institution's leadership and staff, captures the motivations of stakeholders, it is a dead letter as the fulcrum or vector for SP.

\section{Goals and Objectives}

The mission is elaborated through goals and objectives gridded to a timeline for the plan. Goals may be thought of as the plan-based main purposes for realizing the mission and elaborating the vision. Objectives may be thought of as the secondary bases for realizing the goals; objectives are secondary purposes, but in some sense are the primary intervening means for achieving goals. The goals are defined for a period of time together with several operational objectives that realize the goal. An effective strategic plan identifies few rather than many main goals for the institution. One barrier to effective SP is identifying numerous goals and dozens of objectives, making a plan that looks ambitious to readers, funders, and approval bodies, but is in fact a dead letter, because it is hopelessly unattainable, and most often beyond an institution's capacity to measure. A key point here is that goals and objectives must enable the identification of measurable outcomes. This will be important for identifying associated learning and program outcomes and assessments. An institution's strategic plan, to form a system of SP, must create a basis for periodic, as in annual or other periodic, planning. SP includes not simply an institutional plan with goals, objectives, and a timeline. It entails the creation of organized department, school, college, and division annual plans that instantiate the institution's plan and reach to the basic unit and department level. Educational managers should make sure that units develop goals and objectives that align with broader college, division, and institutional strategic goals and objectives.

\section{Desired Outcomes}

Desired outcomes refer to how the goals and objectives, as developed at the varying institutional levels, derive measurable outcomes. In higher education, these will include learning outcomes for academic programs, and also for non-instructional units and operations that the organization's stakeholders need to learn (e.g., how to make a payment, and how to negotiate parking, safety procedures, recycling behaviors on the campus). Second, units also may have non-learning or program outcomes that relate to other activities and operations of the department or office. These might include fund-raising, alumni outreach, clubs and organizations, compliance, communications, and the like. A key quality here is that all parts of an educational institution have one or more learning outcomes to measure, as means of accomplishing the unit's goals and objectives. A second quality is that instructional units (academic departments) have more than learning outcomes. They must, for example, be attuned to and participate in enrollment management (EM) and in effective budgeting. They must have goals for recruitment, retention, and graduation as well as for meeting any identified revenue and cost/expenditure targets. Effective management of SP works to establish uniform participation in institutional priorities and to have them reflected in unit outcomes.

\section{Assessments of Outcomes}

All unit outcomes must be measured. In order for SP to matter, the effort made by the organization must be evaluated for relative effectiveness and in order to identify improvements. Assessment, which refers to evaluation of learning outcomes as well as program outcomes, must occur in order to determine where changes to processes at the unit, division, or institutional levels are needed, as well as where marginal or new funding allocations should be placed. All outcomes must correlate with one or more assessment instruments, which 
enable the unit to generate data on the attainment of learning and program outcomes. The reporting of assessment data, which entails the administration of assessments, must occur on a regular basis. Analysis of the assessment data should inform incremental adjustments of a unit's goals, objectives, and outcomes. It also should inform the unit's budget priorities and allocation/re-allocation of operational funding. Key qualities here would include the identification of multi- or cross- unit assessment vehicles, such as survey software, logistical and other means of operating assessments, as in an assessment office, and training unit personnel to think and evaluate utilizing unit level systems and related institutional infrastructure for measurement. Managers must provide training and support to see that assessment occurs, including release time or sufficient personnel/personnel hours to conduct assessments. They must themselves show that measurable goals and quantifiable metrics are the basis for demonstrating institutional success and continuous improvement.

\section{Budget Priorities Tied to the Foregoing Elements}

Effective SP ties budgeting to the planning process (Hoyt, 2009). In order to accomplish institutional and unit goals, money must be put "where the mouth is", as it were. In eras of robust funding, new monies, capital spending, and long-range planning for programming inform planning. In eras of austerity, units argue for reallocations of existing funds. Regardless, the purpose of assessment is to provide data for units (however local or wide) to make their cases for continued or new funding. Later in this paper, different models for funding under SP are evaluated to identify better practice candidates. These include returns on investment, responsibility-based and load-balancing models (Redlinger \& Valcik, 2008; Ringwood et al., 2005). Managers must resist the tendency to "except" themselves from budgetary constraints arising from SP or from participating in SP altogether. Vice presidents and presidents themselves should place their budgets and priorities into the process for SP to work optimally.

\section{Use of Assessment Findings to Affirm or Revise Goals and Objectives}

The sixth key element of effective SP is the use of assessment results to drive incremental change. Planning implementation results in data about outcomes in relationship to goals and objectives. These data justify actions to increase efficiency in a variety of ways. Without quantitative measures of unit efforts to accomplish the institution's plan as elaborated, there is no assurance of effective management or organizational effort. Without changes based upon results to vector improvements, SP lacks a basis for assuring improvements.

\section{Sources of Negative Feedback}

Having discussed the process of SP and six key components for effective practice, the paper now provides a brief discussion of several pitfalls or threats to it. Implementing SP to good practice requires controlling for barriers arising from various factors: faculty motivation, exogenous limits on institutions, and inflexible and formulaic repetition top the list. Such sources of negative feedback can compromise the results of SP in critical ways. Higher education management of SP must consider and account for these forms of negative feedback.

\section{Faculty Motivation}

As Choban et al. (2008), Welsh et al. (2006), and Welsh and Nunez (2005) noted, successful SP requires broad institutional support and motivation to participate. This is not primarily a matter of policy compliance, since the fabric of SP extends to all aspects of institutional operations. The best organizations using SP have leaders who articulate clearly the institution's use of SP in relation to the mission. They have a team of senior, 
middle, and lower level administrators who in turn articulate and gather faculty and staff ideas and interests at the unit level to the process, and they create a culture of demonstrating the salience of SP for the institution.

If unit level stakeholders do not have a positive and sustained motivation for performing associated behaviors, SP drifts to rote practice or worse. Vectoring of unit goals and objectives, the conduct of assessment, and the use of SP data for improvements assume a formal and static quality that may meet reporting deadlines and performance targets, but do not enliven the unit or accomplish much.

To address this pitfall, the unit practice of SP must engage all stakeholders. They must be able to see themselves and their professional interests in the plan. Planning, assessment, and analysis must be parts of the professional duties of unit personnel. These duties should be compensated. Key roles should rotate. There should be an investment by the unit and its division in training and developing related consensus on the role of SP in relation to stakeholder interests and careers at the institution. The unit's planning should result in verifiable data, appropriate attention from broader level units of which the local unit is a part, gains for improved performance, attention to long-range interests, and appropriate recognitions and consideration in key stakeholder performance evaluations. These are some of the main means by which to avoid this form of negative feedback.

\section{Exogenous Limits on Institutions}

Institution and/or its units have incomplete control. Cooke and Lang (2009) identified that external stakeholders, governmental bodies in particular, overdetermine the context for SP in Canadian community colleges, noting pointedly that "The monopsonistic power of a provincial government ... trumps strategy". A similar line of analysis is pursued by Sirat (2009) in a discussion of Malaysian higher education. Public funding (for public institutions), unfunded mandates for education, and falling public support for federal/nationally-funded financial aid top the list in the United States. Finally, the United States has seen drastic cuts in federal and state grant and loan support for students with lower socioeconomic status. This factor increases the burdens on higher education institutions to allocate scarce dollars to more students.

In an era of twin requirements, diminishing public support for public funding of higher education and increased public insistence on transparency and accountability, public institutions must engage in SP. Annual planning only extends this practice to provide increased mechanisms for fulfilling the demands of funding organizations, lawmakers, and accrediting bodies.

One little discussed factor in this regard is that state legislatures may not fund, as in actually appropriate increased higher education budgets, in a manner that lends itself to rational planning. For example, in the author's home state, state legislatures have finalized higher education budgets after the fiscal year has begun.

A second factor arises from the era of transparency and accountability in public funding. These concepts have elevated the practice of compliance and auditing to the status of a constant "state of accountability" if not emergency. State auditing teams are housed for months on end inspecting institutional processes for audit findings. While this process has potential benefits, much of the human capital needed to drive planning and related decision-making is taken away to manage compliance operations. In addition, there are numerous federal, state, and local mandates, often unfunded, that require scarce human and financial capital to fulfill their requirements. This add-on to planning is an exogenous limit on what else the university or college might well do in the absence of funded and unfunded mandates.

To address these challenges requires institutions to accept the exogenous variables as opportunities, even 
if most of them appear as threats on initial analysis. Requiring institutions to do more with less, to accomplish statutory requirements that come without funding, and to enable increasing number of students without means to attend increasingly costly courses and programs of study accents the need for SP and related practices.

\section{Inflexible and Formulaic Repetition}

SP can amount to formulaic and empty repetition, becoming a practice that replicates bureaucracy, if indeed it does not create it. For dozens of units to engage in planning, with associated draft plans, feedback and revisions, and reporting of plan results, in a cycle of deadlines, and on top of all the other substantive activities of the units, is a tall order. To require annual instantiations of the SP process creates a "reporting job" that does not in itself generate enthusiasm, add extra hours to the day in which to work, or result in pay increases or promotions. These motivational tendencies can result in formulaic repetitions of planning that meet desired form but have sub-optimal impact. SP can then become its own self-fulfilling structure of negative feedback for institutional improvement and stakeholder morale.

How do we encourage and manage SP to good and better practice within these typical constraints? Kezar (2005) noted the value of SP as a process of organizational learning across three phases of exploration, implementation, and evaluation. Her discussion stressed the value of facing skepticism among stakeholders about the value of SP. It is not automatic or reflexive but is possible for institutional partners to understand their efforts as part of a history that continues to unfold. Their role is to accept the challenge of continuing quality improvements or allowing the institution to stagnate or drift. Leadership, senior and unit level, must provide and articulate a rationale and rhetoric for SP that ties unit improvement to the institution's and unit's mission, while also weaving in the "shared fate", not as in loss of employment but as in achieving professional goals, that makes for salience when SP actions are required.

\section{Addressing Negative Feedback}

Having surveyed some sources of problems for management of SP, the paper now turns to describe elements of "the science of planning", or candidate practices for effective SP in higher education. Effective SP incorporates four basic administrative elements to align practice with an institution's mission: (a) local ownership of annual plans; (b) reallocations based on assessment of unit performance; (c) synergy among units and across divisions of an institution; and (d) resource allocations centered on unit responsibility for institutional investments (budget inputs) in relationship to value added.

\section{Local Ownership of Annual Plans}

To extend faculty and administrative motivation, SP should incorporate flexibility and autonomy at the unit level (department or office), together with proactive reception and the absence of scapegoating by higher authorities (college, division, and senior administration). This aspect of aligned planning includes the need to provide some timeline of anticipated gains for units that invest in the process, and a mechanism for identifying and addressing units that underperform.

In order to avoid issues of stakeholder motivation and formulaic repetition, SP should honor and respect the integrity of the higher education institution. It should originate planning at the unit or local level. All units prepare unit plans, ideally on an annual basis. These plans are the bases for broader levels of planning, at college, or division, or wide area levels. Vice presidents prepare plans that incorporate, respect, and value the needs and goals of their component units. 
In tandem, it is important both that performance and assessment metrics be established, their data reviewed, and improvements vectored. It also is an empirical test of SP and annual planning that unit level needs are addressed through the planning process. Deming (1982) seeks to reduce variations in unit level performance through planning that incorporates assessment of effectiveness. This is certainly a best practice for institutional management of higher education.

However, the tendency to use metrics for rewarding "winners" and punishing "losers", or to drive resources to highly effective areas of the institution should be resisted. This typical and zero-sum approach to planning is the greatest barrier to overcome. It is understandable that metrics can be used to justify allocations and reallocations of scarce funds to favored or politically/institutionally designated preferences. However, this undercuts the systemic value of SP and balkanizes institutional stakeholders.

The unit origination of SP should twin with the institutional and management commitment not to use SP to punish or to favor particular units in clientelist fashion. The point and purpose of planning is to raise all ships and to identify synergies among units and across divisions in order to allocate and reallocate funds optimally. Issues of staff reductions, program eliminations, and down- or right- sizing are related but separate institutional processes. In other words, honoring unit plan creation is not simply telling units to engage in SP. It requires directors and mid- and upper- level administrative support for the results of those plans and their intentions. SP to best practice begins at the unit level, and this entails leaders who can integrate the university's, their own, and their units' perspectives in doing so.

\section{Reallocations Based on Assessment of Unit Performance}

SP should focus not only on issues of new funding requests, but also tie annual reallocations to assessment and make reallocation of existing funding a real possibility; this is especially the case in periods of fiscal austerity. Various models for SP budgeting adopted as part of an institution's SP matrix are discussed below. Here the researcher wants to stress the need for whatever model of budgeting that occurs to integrate successfully the levels of new funding, existing funding, and capital funding. This also entails a time horizon of immediate/one-year, short-term, and recurring time horizon issues, as well as long-term planning possibilities.

In an era of shrinking public dollars for many institutions, perhaps in particular public institutions, new funding depends largely upon non-traditional sources of revenue. These go beyond the matter of alumni and donor fund-raising to institution's operating as business entities to house community events, sports and other contests, and concerts. Institutions also can operate actual businesses, such as daycares, elementary or other schools, and productive enterprises of all types (farms, dairies, hospitals, etc.).

Nonetheless, many institutions must identify funds for priorities through reallocations within and across colleges, wide areas, or divisions. This process is not typical for many institutions, whose senior administrators retain control over budgets and typically would view efforts to reallocate from their areas as anathema. It is not easy or fun and typically is initially and finally viewed in zero-sum terms and as a matter for institutional politics.

However, any institution that faces rising expectations and fiscal demands with mostly stable or only minimally growing sources of revenue will need to identify funds to transfer within and among wide areas of the institution's operations. This means that vice presidents on down must develop cultures of innovation and change with assessment data and use those data to demonstrate mission fulfillment. It also means that units may have to "do more with less" and that this does not indicate failure as opposed to institutional integrity combined 
with a willingness to accomplish the mission's strategic goals, including through reallocations that advantage on first glance one area of the university. On second glance, there is no way for any unit of the university to optimize institutional SP without accepting the necessity for reallocations based upon assessment and rational budgeting. Today's "cut" may be necessary in order for the unit that sees funds flowing out to receive more funding and to benefit from the impacts of the reallocated funding over the life of the rest of and/or a subsequent strategic plan iteration.

One test of a higher educational institution is the degree to which its SP culture, based upon local autonomy and stakeholder participation as well as leadership and shared institutional vision, accepts internal reallocations. If this occurs and is not made a matter of logrolling or politics, the institution has adopted a SP practice that sees mission fulfillment as basic to the goals of any unit or wide area. In turn, this requires units and areas to see that their longer-term good is bound up with the good of other units in the short-term that require reallocated funding.

\section{Synergy Among Units and Across Divisions of an Institution}

SP should develop institutional networks that cut across offices, departments, colleges, and divisions; this condition correlates with the need for synergy. In particular, workforce planning should link academic administration across the institution's divisions and prioritize synergies between EM and instructional services' units. The need for these networks has been just discussed in an overarching and fundamental sense when touching on the matter of reallocations in times of fiscal austerity or budget shortfalls. However, there is a more fundamental need for institutional units, across the divisions or wide areas, to link their implementations of SP. That is the fact that for many units and areas of the institution to succeed in their goals and objectives will require the active cooperation and success of the other units' goals and operations.

Perhaps the most fundamental example of this matrix of shared interest and fate concerns the overlap between EM as a division and academic affairs. What Cherrey and Clark (2010) discussed as an example of this between student affairs and academic affairs in the aftermath of Hurricane Katrina, should not be viewed as a best practice only in times of institutional crisis or emergencies such as natural disasters. In this day and age, one of increased competition between two- and four- year institutions or between for-profit and traditional universities, no department faculty can wholly or easily benefit from viewing program enrollment, retention, and graduation as a task or goal and objective of others. For professors, steeped in their teaching and research, to eschew this vital area of service, that is building bridges with EM units, is folly. For EM units to view themselves as experts of enrollment not needing or benefitting from the contacts, energy, and perspectives of academic faculty, is a huge loss for any institution. Both an enrollment vice president and the sage provost will find it beneficial to "build bridges" across their divisions and to include in institutional and area visions the idea that partnerships between their units are necessary to achieve area and unit goals as well as the institution's mission.

However, the fundamentality of financial affairs as a division with either or both of these might be equally noted. Much the same is true of a university or college's physical plant. The more that we conceptualize a higher education institution as a complex organism, an organization, yes, but one in which the relations among areas and units are more salient than is typically depicted on an organization chart, so much the better.

Moen (2007) and Sullivan and Richardson (2011) presented systems of SP that reach to best practice. Units may adopt a competitive (zero-sum), or collaborative (rising tide helps all ships), or external focus 
(working hard to stave off external competitors), or internal focus (accomplishing the mission, making the institution the best it can be), as possible faces of motivation. Most institutions likely combine all of these, more or less. What is common to successful SP is that planning has an annual component, results in data/results that drive improvements, and that occurs systemically. Leadership participates in and uses the results of SP to guide mission and vision fulfillment and budget scarce resources. A university priority template to create performance indicators (Moen, 2007) and to tie SP to goal-setting for employees (Sullivan \& Richardson, 2011) also becomes a necessary condition for effective planning.

\section{Resource Allocations Centered on Unit Responsibility for Institutional Investments}

SP requires the integration of cost accounting and estimates for the value of non-instructional, non-revenue generating units. Models of responsibility-centered budgeting (RCB) (Zierdt, 2009), load-balancing, and returns on investment are relevant in this regard. RCB begins with the assumption that each unit should generate revenue to pay for the costs of running that unit and own those revenues for this purpose. It encourages what Zierdt (2009) called "entrepreneurialism" and allows for "autonomy". Excess revenues from units that generate profits along with other institutional revenue sources can fund units that have inadequate revenues. As Zierdt (2009) noted, “One of RCB's most defining characteristics is how it makes the campus community aware of the actual costs...".

Another similar approach is termed "return on investment" budgeting (Redlinger \& Valcik, 2008). It focuses on the costs of employees in terms of pay, salary, and other benefits, as well as the revenue produced by the employee as estimated by institutional metrics (teaching, research grants, service, etc.). This approach needs to be sophisticated further to include non-instructional units, non-student sources of revenue, and a more nuanced understanding of "instructor costs" as well as "instructional service revenue streams". Nonetheless, it also shines a light on the fact that institutional operations have costs that cannot be considered a surd.

Ringwood et al. (2005) discussed "load-balancing" as a mechanism for allocating human capital to meet an instructional unit's SP initiatives. The basic idea is that the traditional understanding of a faculty member as a subject-matter expert is now wholly inadequate to the needs of many higher education institutions. It also is inadequate as a conception for management/administration. Institutions must have the flexibility to deploy expensive assets according to different modalities of professional activity. EM, administration, and service are not typically appreciated bases for faculty endeavor. However, in the 21 st century, it is not only possible, but also likely that many institutions will need to provide different ways for faculty to meet their workload. These might include working with the enrollment division to increase the program's profile in the community, co-chairing a department or coordinating an important unit activity, such as assessment or course scheduling, or providing service to the unit in developing major program, unit, or campus initiatives. These activities may provide as much or more value to an institutional unit than teaching a particular course section in a particular term or over a period of time.

\section{Conclusion}

The foregoing discussion offers a number of elements that tend to produce effective SP, as they are implemented and used. To conclude this paper, they are presented here as candidate best practices:

1. Periodic updating of the institution's mission and vision;

2. Necessary and sufficient consensus among institutional stakeholders on the mission and vision's contents; 
3. A commitment to planning of fewer rather than many goals and objectives for practical effort;

4. Annual or more frequent periodic iterations of planning under a given strategic plan;

5. Outcomes, related to the goals and objectives, that are measurable;

6. An insistence that all units of a higher education institution, non-instructional as well as instructional, have learning outcomes;

7. Measurement of outcomes fulfillment together with ongoing analysis and quality improvements based upon assessment data;

8. Basing budget requests and allocations on assessment results in relationship to funding requirements for meeting unit goals and objectives;

9. Tying SP to workforce development and employee professional development and goal-setting;

10. Originating planning at the unit level, meaning a program or department;

11. Vectoring improvements based upon assessment so that unit level needs find institutional support;

12. Avoiding zero-sum usage of planning to identify "losers";

13. Tying budget reallocations to SP and assessment;

14. Creating synergy across institutional colleges and divisions through SP, in particular between academic affairs and EM divisions and units;

15. Integrating metrics that provide valuations of unit operations, inputs and outputs, based upon a defined budgeting philosophy and approach, such as responsibility-based budgeting.

It remains unlikely that higher education institutions will be freed of the need to plan and to optimize the SP process. In point of fact, this paper has argued that SP managed to best practice and taken to heart by institutional stakeholders operates to assure greater fulfillment of an institution's mission and vision. Managing SP to better practice can guarantee that student learning occurs to a greater level of quality and fulfillment of the trust placed in colleges and universities by public and private constituents of higher education.

\section{References}

Aloi, S. L. (2005). Best practices in linking assessment and planning. Assessment Update, 17(3), 4-6.

Cherrey, C., \& Clark, E. C. (2010). Strategic planning: Renewal and redesign during turbulent times. New Directions for Student Services, 132(Winter), 75-85.

Choban, M. C., Choban, G. M., \& Choban, D. (2008). Strategic planning and decision making in higher education: What gets attention and what doesn't. Assessment Update: Progress, Trends, and Practices in Higher Education, 20(2), 1-2, 12-13.

Cooke, M., \& Lang, D. (2009). The effects of monopsony in higher education. Higher Education, 57, 623-639.

Deming, W. E. (1982). Out of the crisis. Cambridge, M.A.: Center for Advanced Engineering Study, Massachusetts Institute of Technology.

Hoyt, J. E. (2009). Integrating assessment and budget planning processes: A good or a bad idea? Assessment Update, 21(5), 9-10.

Kaufman, R. (2008). A practical definition of ethics for truly strategic planning in higher education. New Directions for Higher Education, 142(Summer), 9-15.

Kezar, A. (2005). What campuses need to know about organizational learning and the learning organization. New Directions for Higher Education, 131(Fall), 7-22.

Leimer, C. (2012). Organizing for evidence-based decision making and improvement. Change: The Magazine of Higher Learning, 44(4), 45-51.

Moen, D. M. (2007). Planning for transformation. New Directions for Higher Education, 140(Winter), 63-73.

Redlinger, L. J., \& Valcik, N. A. (2008). Using returns on investment models of programs and faculty for strategic planning. New Directions for Institutional Research, 140(Winter), 93-108. 
Ringwood, J., Devitt, F., Doherty, S., Farrell, R., Lawlor, B., McLoone, S., ... Ward, T. (2005). A resource management tool for implementing strategic direction in an academic department. Journal of Higher Education Policy and Management, 27(2), 273-283.

Rosa, M. J., Pedro, M. S., \& Henrique, D. (2005). Defining strategic and excellence bases for the development of Portuguese higher education. European Journal of Education, 40(2), 205-221.

Seymour, D. (2011). Tough times: Strategic planning as a war canoe. About Campus, 16(4), 30-32.

Sirat, M. B. (2010). Strategic planning directions of Malaysia's higher education: University autonomy in the midst of political uncertainties. Higher Education, 59, 461-473.

Sullivan, T. M., \& Richardson, E. C. (2011). Living the plan: Strategic planning aligned with practice and assessment. The Journal of Continuing Higher Education, 59, 2-9.

Taylor, J. S., De Lourdes Machado, M., \& Peterson, M. W. (2008). Leadership and strategic management: Keys to institutional priorities and planning. European Journal of Education, 43(3), 369-386.

Welsh, J. F., \& Nunez, W. J. (2005). Faculty and administrative support for strategic planning: A comparison of two- and fouryear institutions. Community College Review, 32(4), 20-39.

Welsh, J. F., Nunez, W. J., \& Petrosko, J. (2006). Assessing and cultivating support for strategic planning: Searching for best practices in a reform environment. Assessment and Evaluation in Higher Education, 31(6), 693-708.

Zierdt, G. L. (2009). Responsibility-centered budgeting: An emerging trend in higher education budget reform. Journal of Higher Education Policy and Management, 31(4), 345-353. 